\title{
The Role of Strategic Planning in the Transformation of University's Education
}

\section{Mohammad Sadik}

Department of General education, College of education and languages, Lebanese French University, Erbil, Iraq mohammadsadik2018@gmail.com

\section{Hoshiar Marouf}

Department of Business Administration, College of Administration and Economics, Lebanese French University, Erbil, Iraq

hoshiarmarouf@hotmail.com

\section{Adnan Fadhil Khaleel}

Department of General education, College of education and languages, Lebanese French University, Erbil, Iraq

afk.Ifu@gmail.com

\section{ARTICLE INFO}

\section{Article History:}

Received: 25/6/2020

Accepted: $27 / 7 / 2020$

Published: Spring 2020

\section{Keywords:}

Strategic

university

transformation

education

plans

academic

\section{ABSTRACT}

Strategic planning at the university level is supposed to ensure a comprehensive institutional transformation in higher education that carries a functional integration between education, research and ethics in a dynamic process. This planning adopts theoretical and applied topics simultaneously and interact with the environment in all its natural, economic, social, cultural, political and health dimensions.

Here, the plans must be made to ensure strategic developmental transformations in all the structural 
Vol. (5), No (2), Spring 2020

ISSN 2518-6566 (Online) - ISSN 2518-6558 (Print)

Doi:

10.25212/Ifu.qzj.5.2.37 relationships of the university within its various scientific and administrative formations and between its basic functions in higher education and scientific research.

So it is necessary to integrate the vision and mission of a university with the implementation strategies at different levels of departments, centers and other initial academic units up to colleges and boards. Comprehensive coordination plans designed to cover long periods of more than five years, medium periods of three to five years and short annual plans

This process has to be undertaken directed to ensure a sustainable growth of the university in both productive and absorption capacities.

\section{INTRODUCTION}

Planning in general, frames the administrative process at the university both when it is strategic to focus on the basic axes of development and also when all the interests of the university are to be included differently in times of the target transformation periods. Strategic planning for the university is a necessary and sufficient condition to build this institution and keep pace with the developments in other universities across the world. It achieves the interaction between the activities of higher education and scientific research in an ethical and dynamic integrated framework.

What distinguishes the strategic planning at the university level from other areas is that academic education and scientific research accompanying it analyze the theoretical and applied topics at the same time and within the interactions between the university and the environment in its various dimensions of natural, economic, social, cultural and political concerns. 
However, all this requires a precise and fruitful identification of the problem of research and education by relying on various references, sources and experiences in terms of subject, time and location. There, we can see how research and education interact through the university's development plans and within a local and external academic competitiveness that, in a favorable environment, can raise productivity levels in all sectors and can provide a wide range of employment opportunities.

\section{Research Problem}

The research problem can be identified by pondering on the following tasks.

1. To identify the role of strategic planning in teaching and scientific research in the university.

2. To evaluate the position and role of the university with respect to scientific and technical interaction with other local and international universities.

3. To assess the obstacles in higher education and scientific research activities in the university.

4. To review the process of strategic planning in the university in terms of preparation, implementation and follow-up.

Research Goals:

1. Determining the justifications for strategic planning in the university.

2. Linking strategic planning processes with teaching and scientific research activities in the university.

3. To raise the role of the university in the development of its environment and all its economic, social, political and cultural dimensions.

4. Increasing the compatibility between scientific and technical competencies of graduates and the requirements of the labor market. 
5. Intensifying academic links with other educational institutions inside and outside the region.

Rationale of the Research

The research focuses on the necessary transformations that are supposed to be achieved in the role of universities, which remain within the traditional stagnant frameworks and curricula that made teaching take place according to the pattern of indoctrination and based on a few pages, many of which still transmit outdated information and provide research for academic promotion and widening the gap between the university, on the one hand, and the society, the economy and politics on the other hand, and the harder when the changes imposed without prior plans engage with the traditional formulas in progress to become a natural extension of these formulas or as described by cases of projection of the hypothesis and this is what happens with the indicators of both summer training for students and continuing education for graduates and quality assurance for teachers.

Research Method The research relies on descriptive analytical methods based on the available reality of information, publications, studies and theoretical and applied contributions derived from books, periodicals and electronic information sources (Internet).

\section{Contents}

First - An Introduction to Educational Strategic Planning

Second- The importance of Strategic planning for the university and its importance.

Third - The environment and its interactive impact on strategic planning.

Four- University aspirations, vision, mission and values.

Five - Axes of strategic activities and information analysis.

Six - Identification of strengths, weaknesses, opportunities and threats (SWOT). 
Seven - Goals, objectives, plans and programs.

Eight - Implementation of the strategic plans and follow-up.

\section{First - An Introduction to Educational Strategic Planning}

Most often the term "strategic planning" in the context of national education development referred to countries and agencies which have been engaged in planning and managing of the development of education systems more and more strategically, due to many reasons, including the following: First, plan of all the necessary activities, however without necessarily achieving the expected results and ultimate goals. Secondly, due to the pre-conceived notion that more resources will help in achieving the better outcome. Though, how the resources will be used also matters. Thirdly, limitations of advanced planning. One should to make decisions based on balanced decision-making process. One cannot be absolutely sure that there is a "perfect way" to conduct strategic planning. However, what is generic to strategic planning and management that there are specific steps involving activities carried out in a sequence. Any management involves four basic stages: analysis, planning, implementation and evaluation. In the education sector, the management operations related to "upstream", planning work consist of: (i) system analysis; (ii) policy formulation; (iii) action planning.

In common understanding planning is a process whereby a direction is mapped and then the ways and means for following that direction are specified. There are many forms of planning with several types of activities involved in this process. A plan is the product of the planning process and can be defined as a set of decisions about what to do, why, and how to do it.

Over the period, the context in which education planning is performed has been evolved, some of which include: All education systems, in varying degree and intensity, are subject to rapid changes. Frequently those changes are driven by globalization, the marketization of some educational services, IT development, competitions, shift of traditional values and paradigms. The planning cycle has 
become brief, and frequent. This involves the need for planning to be malleable and continuously adjusted to the changing demands of the society and individuals. There is a plethora of plans and programs in many countries. Frequent changes of governments with differing agendas, numerous international and regional initiatives (e.g. MDG, EFA, ESD, etc.), the search for resources and results, and the multiplicity of partnerships, to name a few, lead to a diversity of the planning processes and subsequently numerous, and often fragmented development programs.

\section{Second - Strategic Planning in the University and its Importance}

The distinctive features of the strategic plans, especially for the upcoming shifts in the functions of the university and its responsibilities towards individuals, society and the economy will determine the importance of these plans. Accordingly, we need to address the following two issues, respectively:

1. What is strategic planning in the university?

2. The importance of strategic planning in the university.

\section{What is Strategic Planning in the University? (1)}

In general, strategic planning is understood to be a long-term process in which established objectives lead the way of mobilizing current and potential resources through a series of phases, beginning with a survey of the current situation, identification of the future vision and a quantitative and descriptive analysis of the strengths and weaknesses of the internal environment, opportunities and risks. In the external environment, a strategic change map is formulated, which is subject to specific implementation mechanisms and specific measures of follow-up, whether at the level of business organization or at the level of a sectoral, regional or national economy.

So far one can say that the strategic planning in the university is a process of guiding the university with all its academic and administrative facilities, scientific, technical and financial to achieve its objectives through the mobilization of economic, social, 
cultural, scientific and technological resources, so as to ensure the maximum benefits at the lowest costs for the interests of teachers, students, graduates, administrators and other beneficiaries of the activities of the university wherever they are inside or outside the institution in general.

Here, the success of strategic planning is depended on several factors, the most important of which are the following (2)

a. Specialists with high qualifications for leading positions in the university's scientific, administrative and technical organizations and according to their expertise, competencies and ambitions.

b. Community: Includes all the stakeholders mentioned immediately and thus depends on the extent of their affiliation and their response to the University's directions the success of the approved strategic plans.

c. Available facts: which are supposed to be accurate and comprehensive for all matters related to the university's activity for the requirements, energies and specific directions.

d. preparation of the strategic plan by providing all its details developed with a statement of importance, requirements and alternatives, which must be advanced gradually by the departments, colleges and boards of the university.

e. The plan is usually linked to the university's emergence and development, in line with its inherent energy, human, natural, scientific and technological reserves, and flexibly with environmental changes.

Moreover, the strategic planning process in universities and colleges offering higher education usually proceeds according to the following model.

a. Forming a high committee for strategic planning. This committee is supposed to be composed of specialists, experts and interested in planning processes specified from 


\section{QALAAI ZANISTSCIENTIFIC JOURNAL \\ A Scientific Quarterly Refereed Journal Issued by Lebanese French University - Erbil, Kurdistan, Iraq \\ Vol. (5), No (2), Spring 2020 \\ ISSN 2518-6566 (Online) - ISSN 2518-6558 (Print)}

different scientific departments in the colleges, and include representatives of external stakeholders and a member of the financial management of the university.

b. Drafting the mission and vision of the College: The two must be formulated in a clear manner based on the philosophy of the university and the college and in consultation with the departments of the college. All stakeholders, internal and external, should participate in the formulation of the vision and mission.

c. Environmental survey and SWOT analysis, which includes Strengths, Weaknesses, Opportunities and Threats, that usually come from the external and internal environments of the organization. The Strategic Planning Committee assesses the difference between the current situation and the desired future according to the mission.

d. Benchmarking: Universities usually choose a similar international higher education institution to compare their performance through Key Performance Indicators.

e. Strategic programming: which addresses the key issues related to the central objectives with an action or implementation plan or to achieve the specific vision and mission and fill the gap identified after SWOT analysis. Here the operational plan includes a certain number of projects, and a detailed roadmap designed for each project.

\section{The Importance of Strategic Planning for the University (3)}

Strategic planning is generally concerned with the main objectives of the organization, which include the human, financial and operational aspects of resources and how they support the mission and vision statements. Here, the importance of such planning is in all areas, especially higher education, as shown below:

a. The university administration and its scientific, technical and administrative units declare their vision, mission, goals, objectives, values and plans. This is what 
promotes transparency and increases the cases of assurance in the work (scientific and administrative), reduces the negative effects of investment risks in higher education and reveals the points of error, shortage and negligence. It acquaints the departments of the university and its employees of their responsibilities to achieve the vision, missions and goals they have previously approved.

b. Intensifying the training programs of workers and to qualify them scientifically, technically and administratively in order to develop their capabilities in research and development (R\&D), increasing their products of inventions and innovations, which helps in the development and spread of modern technological methods and means, all while adhering to the standards and conditions of total quality and flexibility in the provision of basic services.

c. Guiding the processes of education, research, consultancy and training as integrated activities in all dimensions. Thus, the lectures are strengthened only when after they have actually turned into meaningful scientific research and fertile areas for dialogues about the prevailing problems in society and the world and how to interpret and address them.

d. Identification of actual and potential capacities and opportunities for competence and innovation Here, strategic planning can achieve a sustainable competitive advantage for the organization by converting the potential reserves of resources to actual reserves, raising productivity rates

e) Ensure sustainable education through commitment to continuous improvement and development of the curriculum, attracting the students in the class, minimize the periods of disruption and absenteeism and use the time allocated for lectures wisely and efficiently.

f. Emphasize the role of industrial, agricultural and commercial colleges, institutes and schools for taking vocational training curricula to the widest geographical area, including remote areas. This will in turn help to spread productive activities and diversify the professional qualifications of the population, thus increasing the 
employment opportunities for all who will be characterized by high flexibility in the demand for jobs according to changing market needs.

g. Develop university information about the labour markets in order to increase the compatibility between job specifications and the qualifications of graduates.

h. Adopting a methodology based on openness to individual and institutional initiatives and predicting the future needs of society.

i. Ensure the actual and accurate performance of approved plans and programs through continuous follow-up as regards the implementation of these plans and programs in the light of the objectives and criteria set.

j. Ensure participation of all sectors of society, minorities and different income groups in higher education.

It is noteworthy here that the last few decades have witnessed major transformations in all aspects of life in the world. Universities and other higher education institutions have faced fundamental changes in their internal and external environments, with regards to the role of governments and international organizations. This has been achieved by rapid technological development and its implications on academic programs because of strategic planning. It is a fundamental and imperative necessity to adapt to the requirements of new environments. Features of the strategic planning of higher education institutions are different from the strategic operations planned in business institutions, as shown below.

a. The strategic shifts in higher education extend to all areas of human resources development and achieve fundamental shifts in science and technology through education, scientific research and training. This requires longer periods than raising productivity efficiency and maximizing profits for businesses.

b. The university organizations are characterized by their graduation from branches to departments and then to colleges and academic boards and this makes strategic planning in higher education comprehensive and integrated of the university's 
scientific, technological and administrative activities, leading to the mobilization of the potential of workers, students and other stakeholders. All of this can be achieved by building the bottom-up planning process, where in everyone contributes to it and also towards all the projects and programs.

As for business, top-down strategic planning may be preferred because of the power of the central authority and the need to narrow the scope of certain topics to maintain maximum profitability.

\section{Third - The Environment and its Interactive Impact}

The effects of the environment have different areas, elements and trends, which must be addressed as overlapping phenomena with all their pros and cons. In terms of the areas in which the impacts are extended, the following environmental formations appear. (4)

1. The internal environment (within the location or locations of the strategic mission).

2. Surrounding environment (for strategic mission site or sites).

3. General environment (external to the site or sites of the strategic mission).

The interrelationships of these areas can be illustrated in the following form (Fig. 1). 


\section{QALAAI ZANISTSCIENTIFIC JOURNAL}

A Scientific Quarterly Refereed Journal Issued by Lebanese French University - Erbil, Kurdistan, Iraq

Vol. (5), No (2), Spring 2020

ISSN 2518-6566 (Online) - ISSN 2518-6558 (Print)



Fig. 1

There are certain elements within each previous environmental field. These elements affect each other and affect the elements of the next (or other) environmental field.

Here, the strategic planner is supposed to study elements of each of the three previous environments and try to reach what we might call the process of environmental equivalence of strategic planning. This process includes the following known conditions of equivalence.

\section{Reflexive condition}

A single environmental field reflects itself in all its elements and details. This is achieved when there is some kind of interaction between the elements and the structure of the field in question becomes balanced in terms of the effects of each major or secondary element as well as in the structural relationships of these effects 
and the sources of their generation. As a result, there is some harmony in the effects of the universal set elements of a single environmental domain. This harmony will ensure the continuity of the characteristic or condition in the field concerned.

\section{Symmetric Condition}

The effect of each element, whether within the partial set or the universal group, corresponds to the effect that comes from another element that is opposite in direction and equal in force or efficiency.

This condition is applied to the corresponding effects within a single environmental domain, thus perpetuating the reflection condition for that field, as well as to the interrelationship of the three domains. That is, between the internal environment and the surrounding environment and the general external environment.

If the symmetric elements of a single environmental field concentrate the structural equilibrium and thus the reflectivity of a single environmental field, the symmetry of the corresponding environmental field increases in efficiency and stability when the condition of reflectivity is met for each of the three domains.

\section{Transitive Condition}

This condition relates to how the effects of a single environmental domain are transferred to a third domain through an intermediate domain. For example, the impact of the internal environment domain is transferred to the external public environment through the surrounding environment. This can be applied from any other domain to a third domain and through an intermediary domain.

The symmetric requirement of each of the three domains will perpetuate the transition condition.

Thus, each of the three conditions for environmental equivalence supports each other. 
To illustrate a mechanism for achieving this parity, we refer to the trends of impacts generated by the elements and areas contained.

Trends of impacts concerned are as follows.

1. Positive Feedback

2. Negative Feedback

\section{Positive Feedforward}

\section{Negative Feedforward}

Backward feedback is concerned with the reversal of the impact of a decision, behavior or directing positively or negatively to its source materially or morally over a certain period of time. On the other hand, the effect generated by forward feeding is transferred from one field to another without returning to the source of the occurrence within a certain period of time.

Four types of environmental impacts are subject to backward and forward feedings:

1. Participation in decision making and in team works. Full positive feeding appears.

2. General acceptance: This is often in response to the public opinion or enthusiasm of the majority or as a result of the control of the source of primary influence or favoritism of this source (personal, social, political or economic). Here it shows a moderate positive.

3. Conditional acceptance or initial resistance. Acceptance is restricted by a condition or resistance may occur, but it adopts methods of dialogue (personal or material). An adjustable positive or moderate negative feed appears.

4. Rejection, hereby show total negativity. 
To identify and treat these conditions, the strategic plan is supposed to take into account the element of time, because what is considered positive in one period may become negative in another period or vice versa may turn what is negative in one period to what can be positive in another period. Therefore, it is necessary to prepare short and medium-term plans that aim at a targeted and specific change of impacts or negative feeds to positive ones by avoiding the reasons for rejection and supporting the reasons for acceptance. The strengths and prominence prevail and the positive opportunities dominate at the expense of weaknesses, uncertainty and inherent risks.

With regard to the internal environment of the college or university in general, it is known through the current mission and the historical development of the institution in any of the data of the previous mission. A few institutions have tasks similar to their original statement, which is one reason why reviewing the mission is necessary at the beginning of the strategic plan.

Once the draft plan is ready for public presentation, the planning committee should return to the stakeholders and clarify the various components of the plan and how to use it

\section{Four - University Aspirations, Vision, Mission and Values (5)}

The University's vision, mission and values depend in particular on its core aspirations in strategic planning.

\section{The university's basic aspirations}

These aspirations include the ambitions of teachers, administrators and students to achieve the highest scientific, technological and organizational levels that increase their individual competences in accompany with their suitable institutional and environmental capabilities. all this depends on two bases: (a) identifying the changes required over a long and medium horizons and (b)allocating economic, cultural, scientific and technological resources according to priorities that ensure efficiency and effectiveness in achieving goals and objectives. The pivotal and fundamental 
university dedicates its academic values in improving and developing the services of higher education and scientific research by following the advanced methods and using the best technological means to excite students to reach professional and recognized levels in the labour market and to strengthen their activities on all levels and spaces: local, regional and international.

Strategic planning is based on the following basic factors

a. Vision

b. Mission

c. Values (virtuous and creative academic)

\section{a. Vision}

An university aspires to be a diverse, distinctive and comprehensive institution for education, research, consultancy, training, human development and ethical and intellectual ideals in a context in which individual material and financial aspirations interact with the general human cultural and social requirements (especially for the university). Further this also ensures sustainable education in terms of curricula, stages and research environments, to develop teachers and students to reach the highest international standard which have been approved for advanced universities.

Here, one of the most important aspirations of the university is to achieve the following.

(1) An university should be an integrated institution of education, research and ethical and intellectual development. The university would aim, regardless of its location, to lead human societies and contribute effectively to their cultural transformation. This is usually directed across different domains, methods: local, regional, national and global. As for the area of transport network is concerned, fast and cheap communication should be available throughout the day and night. Here, the university is 
supposed to build, consecrate and promote scientific, cultural and moral traditions, principles and values within a free academic environment in which innovation plays an important role.

So far a sense of academic affiliation and identity can be deepened as a first institutional vision.

(2) Increasing the role of the University in the long-term comprehensive and sustainable development through the mobilization of all sectors of the economy and society and their administrative, social, institutional, regional and spatial formations, and here the university is supposed to guide the curriculum, research, and theses towards the issues, treatments and analyses that serve this developmental role of the university.

Through its continued vision of its leadership role in sustainable development programs, the university can contribute effectively to the economic, social and cultural life of its surrounding settlements in which it is located.

(3) Establishing and developing the human resources on a modern scientific basis relying on specialists in the sciences of psychology, sociology and management University will be mainly interested in preparing research and consultancy in the areas of determining the criteria of employment and performance evaluation and raising productivity and organizing workforce budgets, all in order to recruit and develop the best members in teaching and research staffs, management, and ensuring equal opportunities for all these members in recruitment, personal development, career progress and performance evaluation in all areas of work at the University.

(4) Providing basic services, especially like the following.

(a) libraries which should be rich in diversified and modern scientific references required in the university area. 
(b) publishing houses which will facilitate the scientific products of the university to all parts of the world.

(c) computing facilities, supplies and materials and building databases for various purposes, especially researches, studies and data, while working to strengthen contacts with research centers, universities and other scientific institutions for the purpose of engaging in a competitive global environment.

(5) Developing coordination programs for the participation of society in its various categories, especially businessmen and those with scientific, technological and cultural expertise.

\section{b. Mission}

The mission statements are a clear description of the curriculum's origins, cultural and educational norms, and basic services. The mission statement also includes an explanation of who could become the students of the institution in question.

The mission of the university focuses on the following four concerns.

(1) Creating, developing, applying, and directing knowledge towards creative, economic, social, cultural, political and technological works.

(2) Educating students, deepening their cultures, developing their moral values and increasing their intellectual obligations towards the university, the country, the society, and the legislations in force, taking care of their interests and future prospects.

(3) Strengthening the University's material, technical and financial resources within and outside the University.

(4) As the university works for the public interest therefore the curriculum and its applications and decisions and research activities, consultancy and training should be based on this interest. 


\section{c. Values (virtuous and creative academic)}

(1) Raising generations to love and defend the national interests.

(2) Building academic personality, preserving the cultural identity, developing its values, and enhancing the spirit of citizenship among students, teachers and administrators.

(3) Developing the values of teamwork, participation, job satisfaction, being contemporary and modern.

(4) Taking care of the state of diversity of political, social, economic, cultural, ethnic, religious and sectarian assets and linking this diversity to increase the capacities of all divisions in the university.

(5) Spreading the spirit of positive competitive work among students and teachers with the dissemination of a culture of quality in performance and free and serious scientific thinking and creativity among them.

(6) Developing critical thinking.

(7) Emphasizing the concepts of specialization to produce participants in the fields of teaching, learning, writing and publishing.

(8) Developing of language skills in respect to the basic languages used in the country.

(9) Encouraging spoken and listening skills.

(10) Linking local culture with international culture while preserving the virtuous values of the society.

\section{Five- Strategic Activities and their Information Analysis}

Light is thrown here on the following topics

\section{Axes of Strategic Activities}


2. Axes of Information Analysis

\section{Axes of Strategic Activities}

The following axes can be distinguished.

a. Providing distinctive programs of study (in all the initial and higher stages) of high quality in line with what is emerging in the various disciplines of the universitytheoretical and applied - and all that contributes to the development of society and the rehabilitation of researchers and the promotion of methodological, intellectual and scientific efficiencies.

b. Providing consultancy and research services.

c. Communicating with postgraduates through continuing education courses and vocational training programs and providing facilities for the completion of postgraduate studies inside the country and abroad and to engage in the labour market with perfect qualifications.

d. Integrating the University with society through research, consulting, training and continuing education.

e. Advancing cooperation protocols between the scientific departments and colleges in the university and the corresponding departments and colleges outside the university locally and internationally.

f. As an institution of public interest, it is assumed that the owners (employers) first and then the senior management of the university should prepare an annual budget after deducting the owners' share of profits according to the approved regulations or according to an agreed system, thus achieving financial independence for the university. 
The strategic plan is concerned with many sources of information, the most important of which are the following.

a. The questionnaire forms, which are distributed to the students, teachers and administrators at different levels of the university and employers

b. Field visits and interviews.

c. Group meetings: workshops, seminars, conferences and brainstorming sessions ....

e. Previous experiences in strategic planning.

f. Offices of student registration, human resources, statistics, and scientific and quality assurance that prepare reports, data and assessments on development of teachers, students and graduates.

Key topics included in the requested information are the following.

a. Identification of the strengths and weaknesses of the internal environment and the opportunities and threats in the external environment with reference to situations and events that support the mission, goals, objectives, plans and programs.

b. Recognition of the real needs of stakeholders including owners, administrators, teachers, students and graduates.

c. Manifestation of the impacts of environmental dimensions: PESTING (political, economic, social, technological, institutional and natural) and (effects of globalization).

The data will then be reviewed and the results will be formulated in accordance with the environmental analysis approach. This paves the way for defining goals, objectives and values and thus identifying alternatives and presenting strategic plans.

\section{Six - Identification of Strengths, Weaknesses, Opportunities and Threats (SWOT)}


Strategic planning requires a specification of the internal environment's strengths, weaknesses, and external environment's opportunities and Threats. These four groups are summarized in an acronym - SWOT in order to accurately and objectively identify goals, objectives and plans.

With SWOT 's identification in the university, the following facts in relation to each of strengths, weaknesses, opportunities and threats are respectively recognized.

\section{strengths}

1. Geographical location is strength when the university is located in the urban center and near to other universities and research centres such as the LebaneseFrench University. It is located in the city of Erbil, the capital of the Kurdistan Region of Iraq, and close to three universities and between two of the largest streets of this city.

2. Availability of perfect and enough infrastructure with advanced and professional staff.

3. The diversity of scientific specialties, which are supposed to be organized and directed among the scientific departments and colleges which are adopted in teaching the latest educational technologies.

4. The variety of students enrolled in the study are of different origins.

5. Issuing scientific journals of the university.

6. Giving serious attention to postgraduate studies: Masters, $\mathrm{PhD}$ and professional diplomas.

7. Developing continuous education programs to maintain the permanent development of graduates scientifically and academically.

8. Preparation of training courses on teaching and researching methods for the purpose of professional preparation in education and research. 


\section{Weaknesses}

The following weaknesses can sometimes be observed at the university.

1. Lack of coordination between the registering offices at the secondary schools and the admission departments at the universities, cause a delay in studying in the first stages of university. This leads to a shorter study period.

2. The ineffectiveness of part of the curriculum adopted for the needs of society and the labor market.

3. Lack of training and technical skills, whether at the level of administrators or teachers.

4. The small size of the library in terms of the capacity of the place and the number of references and sources and the lack of electronic library and sophisticated systems for ordering, receiving and classification.

5. Lack of language labs facilitating learning different languages.

6. High ratio of students to teachers with crowded halls in large numbers.

7. The absence of annual or quarterly plans at the levels of teaching staff and scientific and administrative departments, especially for research, seminars, conferences and workshops. This leads to the absence of strategic thinking, whether at the level of departments or colleges.

8. Concentration of students' interest in obtaining a certificate only, without learning and acquiring skills. Consequently, the absenteeism rates are high and the curriculum vocabulary is rarely prepared. In many cases there is less serious preparation for the exams, including the final exams.

9. Extreme weakness in the basic curriculum materials of the university, especially in the basic national languages and computers, created severe difficulties for students in understanding their lectures and further preparing and discussing. 
10. Absence of systematic materials or specialized programs in ethics.

11. Lack of an officially approved and stable institutional monitoring and evaluation system.

12. Decreased efficiency and effectiveness of communications and advanced information systems.

13. Teachers need to pay more attention to scientific research and publishing in refereed academic journals in order to develop their teaching abilities, enrich their lectures and raise their academic ranks.

14. Lack of effective databases to achieve integration at all levels, i.e. between departments and colleges, between colleges and the corresponding departments and colleges in other universities locally and internationally.

\section{Opportunities}

1. The presence of the university in the capital attracts the majority of the population, services and funds.

2. Increasing numbers of high school graduates, looking for admission sites in the university, especially with growing interest of the community for university degree holders.

3. Increasing the local and international orientation towards emphasizing the total quality system for higher education and scientific research.

4. The existence of integrated and perfect legislation for higher education.

5. The safe (internal, surrounding and external) environments of the university would increase the ability of the university to attract professional teachers and smart students. 
6. The financial surpluses resulting from student fees can provide a relatively high potential for self-financing of their regular expenses and for covering an important aspect of the University's development programs and projects.

\section{Threats}

1. Low levels of students who graduate from high school and are at the lowest grades of success. They also suffer from severe weakness in languages and computers.

2. Lack of communication between the scientific departments and their curricula on the one hand and labour markets and conditions and requirements of employment on the other hand, which causes high unemployment rates among graduates further resulting in frustration among students.

3. The university's lack of communication with its graduates causes ignorance of the shortcomings of the curriculum and its practical requirements.

4. Lack of communication with the external community is evident from the weakness of the real orientation towards the surrounding and external environment (economic, political, social, technological and administrative) while preparing curricula and lectures and follow-up references.

5. The bureaucratic complexities that hinder the implementation of many of the university's programs and projects.

6. Insufficient financial and administrative support for the university.

\section{Seven - Goals, Objectives, Plans and Programs (6)}

Objectives are distinguished from Goals in that objectives are specific, measurable, attainable, and directed towards limited spatial and institutional frameworks. These objectives are supposed to be developed in the implementation of certain alternatives and then the choice of the best strategic alternative, which sets a timetable that can be implemented with a relatively high efficiency and effectiveness. One of the main goals of the strategic plans at the university is to ensure the academic 
success of students, which is supposed to be achieved through serious objective tests and the adoption of the latest methods, means and systems available. Further it is aimed to diversify the financial resources of the university in order to devote the independent management of the institution, and improve the infrastructure and educational processes, and encourage community participation by deepening the university's interaction, all its functions in the surrounding community .

Scaling up these goals, deriving precise targets from them, and applying them on a scientific basis require some relevant initiatives to improve graduate participation by transforming them from recipients of information into developers and to be updated in all teaching, research and testing facilities. This requires the establishment of serious interactive relationships with other universities and community organizations at all levels of local, national and international, and the development of a marketing strategy covering all products and services.

The strategic planning process involves two interrelated steps: formulating goals and objectives and defining action programs based on values and institutional mission. This entails engaging with a wide range of stakeholders at the university level and developing a coherent set of institutional priorities, for effective implementation of the plan.

There is a need to monitor implementation, track progress and review the strategic plan as necessary criteria for evaluation and accountability. In addition, it is important that the organization routinely sends report on its progress towards achieving its objectives for all stakeholders.

The overlapping cases of the previous goals and objectives can be clarified more by presenting two goals and a number of objectives derived from them and plans and programs adopted to achieve these goals and objectives.

\section{The first goal}

(Developing the role of the University as one of the outstanding centers to prepare qualified cadres for the labour market). 
Objectives

1. Improving the educational and technological environment and the university infrastructure.

2. Providing students with high quality educational and training services that increase their competitiveness in the labour market.

3. Building bridges of cooperation with business organizations for the labour market.

4. Increasing the effectiveness of curricula and programs in reality and ensure that they meet professional and scientific standards.

5. Continuous improvement in the quality of the educational process and openness to various references and sources of applied knowledge.

6. Rehabilitation and development of human cadres working in the university.

\section{Plans and programs}

1. Supporting the scientific departments with the adopted scientific standards and the applied curricula in the advanced universities in the world.

2. To develop and implement an integrated university follow-up system, which includes the definition of academic standards, measurement mechanisms and assessment methods.

3.To develop and implement a system to stimulate outstanding technical and applied initiatives for individuals and departments.

4. To improve library services (in demand, cataloging, classification, storage and borrowing) and the introduction of modern technological devices and the application of electronic methods of communication and provide references and sources of local and global knowledge in its traditional and electronic forms, all leading to enrich the library with theoretical and applied studies. 
5.To expand health and sports services for students.

6. To conduct the necessary studies to determine the skills and knowledge required for graduates in the labour market.

7. To design and implement practical training programs for students inside and outside the university.

8. Encourage creativity, innovation, brainstorming and self-learning among students.

9. Expanding the use of e-learning, educational media and distance education.

10. Linking curricula with the results of scientific research for teachers to enrich them and to give realism to the curriculum.

11. Developing interdisciplinary joint study programs.

12. Develop effective systems to monitor and measure student participation in teaching and learning process.

13. To promote assessment systems.

14. Preparing continuous training programs to increase the capabilities of the teaching and administrative staff at the university, especially with regards to modern technologies, improving scientific quality in education and scientific research and increasing administrative skills.

15. To develop and implement an appropriate system for evaluating the performance of teachers and administrators.

16. Forming (scientific research teams and committees to discuss theses, curriculum development boards, groups ...) jointly with other universities within and outside the region.

\section{The Second Goal}


(Raising the efficiency and effectiveness of the University as one of the recognized research centers that work to develop participation and cooperation with other institutions and educational and research centers and community institutions at the local, regional and global level.)

\section{Objectives}

1. Expanding research and consultancy and increasing their efficiency and effectiveness.

2. Developing the capabilities of teachers and administrators and take care of their impulses in the field of studies and scientific and applied research.

3. Encouraging university graduates to join masters and doctoral studies.

4. To activate teamwork with researchers and teachers inside and outside the university.

\section{Plans and programs}

\section{Preparation, implementation and follow-up}

A public relations system should be in place, whereby an office be established to coordinate the activities of the different departments in joint research, consultancy and training teams within the university faculties and with other academic and scientific institutions. It also facilitates university orientations to establish productive companies, to arrange contracts with business organizations to support students financially and provide job opportunities after graduation.

2. Developing cultural cooperation agreements and protocols with local, regional and international research institutions. In this way, agreements and programs of cooperation and cultural and scientific exchange for students and teachers and study programs with universities and other scientific institutions, wherever they are, shall be established. 
3. To promote mechanisms to implement joint research strategies and plans at the university level and in different departments.

4. Motivating teachers and administrators to address the solution of community problems through interdisciplinary research.

5. To cooperate with other institutions to conduct applied research and to address local and regional issues.

6. To develop a system of funding and dissemination of outstanding research for teachers.

7. Establishing postgraduate studies to grant the Higher Diploma in specialized research fields as: marketing research, educational counseling, regional relations, regional and urban studies.

8. Developing programs to guide students according to their areas of specialization. The departments should work towards allocating their graduation research mainly towards topics that deal with the current and expected negative problems and phenomena in the region in particular and in the country in general.

\section{Recommendations}

We conclude from this study that strategic planning by virtue of its inherent role in achieving fundamental transformations in the axes of sustainable development of the university, especially higher education, scientific research and ethical model can become the most effective process in raising the level of any university to the levels of discreet universities in the world and this certainly requires dynamic consistency between the institutional foundations (especially the legislative, regulatory and administrative), available resources (human, technological and financial) and the different environmental dimensions among them and the development goals adopted by the university within its foreseeable ambitions. 
After giving a profound thought to all the factors, we recommend the following (7).

1. Continuous comparison between what is planned and what is implemented, especially for the trends, rates and components of change, which leads to determine the deviations of implementation from planning in terms of capacity and analysis of factors and methods of treatment.

2. Adopting scientific measures of costs, quality and productivity, based on many cases that have already been tested on accurate information.

3. Providing all legislative bases by referring to a compatible package of laws, systems and instructions.

4. Developing an effective system for internal and external communication networks with the establishment of sufficient databases.

5. Giving utmost attention to human resources, in their selection, promotion, training and financial compensation in accordance to their performance.

6. Establishing a planning and follow-up office to include strategic planning specialists.

7. Awareness of all stakeholders, including owners and departments (senior and middle and initial supervision and staff), teachers and students of the importance of strategic planning and its material and moral benefits for all and the need to participate in this process.

8. Allocate special financial resources for strategic plans from the determined funds under the direct supervision of the head of the office in charge of strategic planning.

The focus here is on the two central structures. Physical structure for laboratories, libraries and computers. Human structure based on education, training, consulting and information and communication networks. 
This requires reinforcing the curriculum with advanced scientific subjects, providing modern curricula and devoting moral values, noble ideals and academic personality. Individualism according to fair objective criteria along with an integrated view of academic activity to bring together research, studies, consultancy, training and education in real time, which positively reflects on the development of the university and enhance its role in society

9. Developing a timetable for the implementation of plans according to the critical path method (CPM) to facilitate the follow-up and evaluation process.

10. The shift in methods of assessment of students from confining them to traditional exams to methods that reveal the true capabilities of higher learning outcomes, including the participation of workers in production sites and demonstrate the responsiveness of field applications to the curriculum

\section{References and Sources}

Hoshiar Marouf; The Strategic Planning, Dar Wael, Uman,2009, P25(in Arabic)

K. A. Paris; Strategic Planning in the University. 2003 University of Wisconsin System Board of Regents.

\section{https://www.cuhk.edu.hk/u-planning-office/documents/other-strategic-planning/paris-}

\section{3 strat-plan-in-u.pdf}

B. Keith Simerson; Strategic Planning, Praeger, 2011, Oxford, England.P15

Ali Al-sayed Jumaa;(The Strategic Planning of the University Education, The Journal of the Education College, The University of Qanat Al-Swess, July 2012, PP263-264(in Arabic)

Ch. A. Goldman; University Strategic Planning, RAND, P6- 


\section{QALAAI ZANISTSCIENTIFIC JOURNAL}

A Scientific Quarterly Refereed Journal Issued by Lebanese French University - Erbil, Kurdistan, Iraq

Vol. (5), No (2), Spring 2020

ISSN 2518-6566 (Online) - ISSN 2518-6558 (Print)

https://www.rand.org/content/dam/rand/pubs/perspectives/PE100/PE157/RAND PE157.p $\underline{\mathrm{df}}$

- $\quad$ F.Hall; The Importance of Strategic Planning, Strayer University, 2013

https://www.researchgate.net/publication/241688503 The Importance of Strategic Plan $\underline{\text { ning }}$

- University of Guadalajara's STRATEGIC PLAN 2014-2030

https://www.timeshighereducation.com/sites/default/files/institution downloads/strategic plan.pdf

PP17-23, 85-87. Op cit. - B. Keith Simerson;

- S. Maleka; Strategy Management and Strategic Planning Process, Conference Paper, Pretoria, March 2014, PP 4,15.

https://www.researchgate.net/publication/273757341 Strategic Management and Strate gic Planning Process

C. Ong; 7 reasons why schools need strategic planning,

2016

https://www.envisio.com/blog/7-reasons-schools-need-strategic-planning

(4)

66-61Hoshiar Marouf ;op cit PP

(5)

S. Maleka; op cit, P7

B. Keith Simerson; op cit. PP85-86

M. Hassanien (Strategic Planning in Higher Education, a Need for Innovative Mode) · Journal of Education, Society and Behavioural Science , January 2017) 


\section{QALAAI ZANISTSCIENTIFIC JOURNAL}

A Scientific Quarterly Refereed Journal Issued by Lebanese French University - Erbil, Kurdistan, Iraq

Vol. (5), No (2), Spring 2020

ISSN 2518-6566 (Online) - ISSN 2518-6558 (Print)

file:///C:/Users/user/Desktop/HassanienSP.pdf

C. Ong; op cit

by K.E. Hinton: A Practical Guide to Strategic Planning in Higher Education, the Society for College and University Planning, 2012, P10

https://oira.cortland.edu/webpage/planningandassessmentresources/planningresources/S CPGuideonPlanning.pdf

(6)The Arabic Institute for Planning,Al-Kuaet,2016

http://www.arab-api.org/images/training/programs/1/2016/362 P16044-9.pdf

https://www.hartnell.edu/sites/default/files/u770/strategic-planning-in-higher-educationbest-practices-and-benchmarking-2013.pdf

Strategic Planning in Higher Education - Best Practices and Benchmarking HR Hanover Research, July 2013

SAKARYA ÜNIVERSITESI 2009-2013 STRATEJIK

PLAN TASLAĞI

A road map for strategic planning in higher education institutions

SAKARYA ÜNIVERSITESI 2009-2013 STRATEJIK

PLAN TASLAĞI

A road map for strategic planning in higher education institutions

Ercan Oztemel and Harun Taşkin : A road map for strategic planning in higher education institutions, Conference: 6th International Research/Expert Conference: QUALITY , 2-5 June 2009, At Neum / Bosnia Herzegovania.

https://www.researchgate.net/publication/280532435 A road map for strategic plannin $\mathrm{g}$ in higher education institutions

(7) 


\section{QALAAI ZANISTSCIENTIFIC JOURNAL \\ A Scientific Quarterly Refereed Journal Issued by Lebanese French University - Erbil, Kurdistan, Iraq}

Vol. (5), No (2), Spring 2020

ISSN 2518-6566 (Online) - ISSN 2518-6558 (Print)

https://www.cia.gov/library/abbottabadcompound/3F/3F32C943EFDAEE606CFA5367D36924D5

J. Smith; The K.P.I. book, Insight Training Limited, Stourbridge, UK,2001.

http://www.pro- u4ot.info/files/books/finance/KPI Book Sample.pdf

D.Velimirovića, M. Velimirovićb and R. Stanković

ROLE AND IMPORTANCE OF KEY PERFORMANCE INDICATORS MEASUREMENT

Serbian Journal of Management 6 (1) (2011) 63 - 72

P. Elwin and R. Hirst: Guide to key performance indicators Communicating the measures that matter, PC, UK,2007.

https://www.pwc.com/gx/en/audit-services/corporatereporting/assets/pdfs/uk kpi guide.pdf

Strategic Planning Council

https://www.angelo.edu/services/strategy/strategic planning council.php

يـوختهـ:

يلانى ستراتزى له سهر ئاستى زانكو دهبى گورانكاريهكى ريكخراوهيى گشتگر بیى

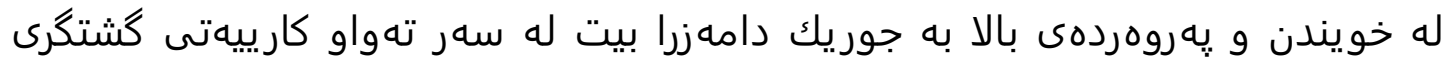

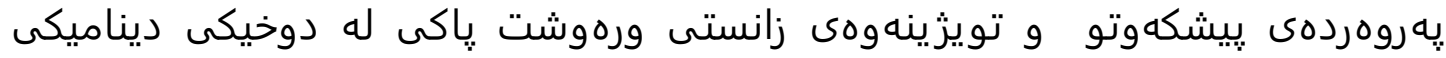

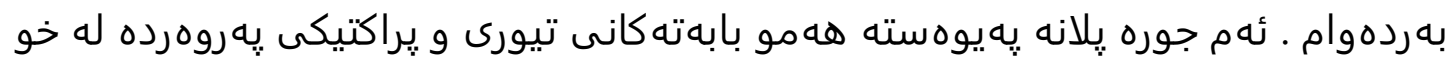

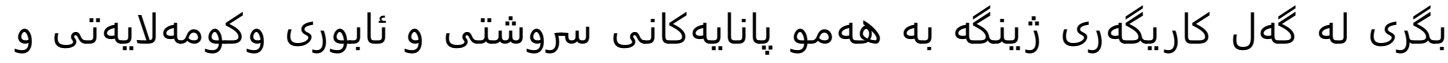
كهلتورى و سياسى و تهندروستى.

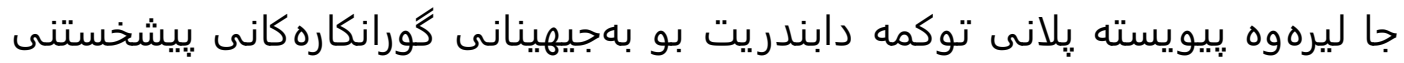

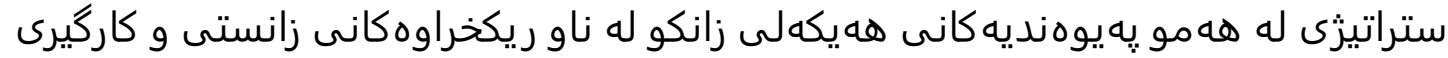

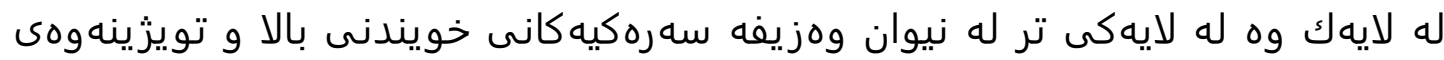


بهم گويره يُيويسته ههر يهك له يِيشبينين ونامهى زانكو ببهستريت به ئهو ستراتيزانهى

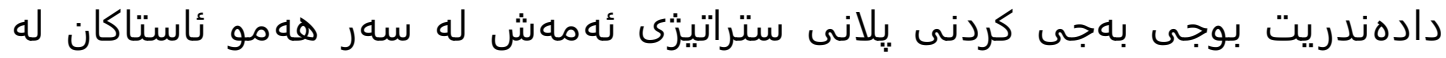

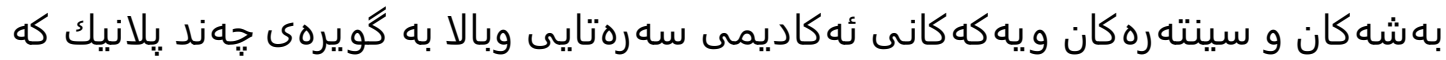

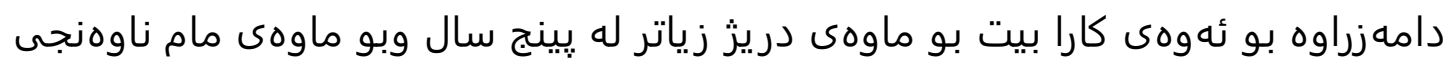

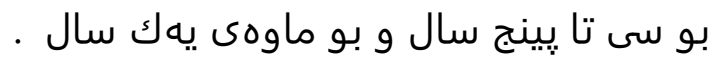

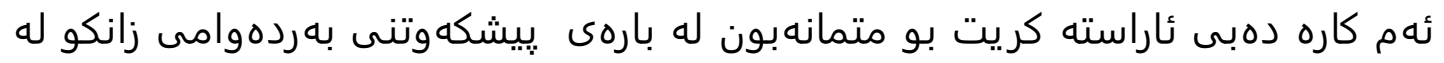

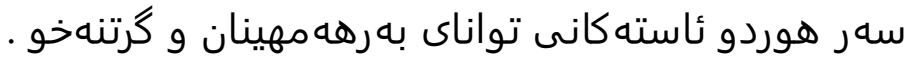

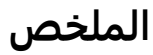

يفترض بالتخطيط الاستراتيجي على المستوى الجامعي تحولا مؤسسيا شاملا في التعليم

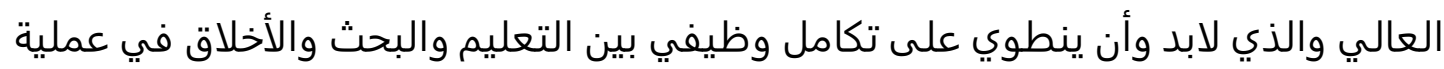

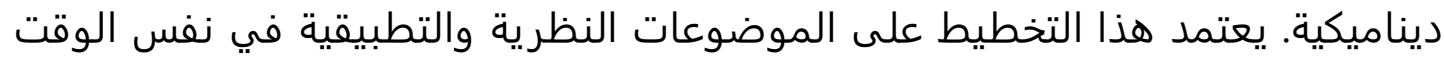

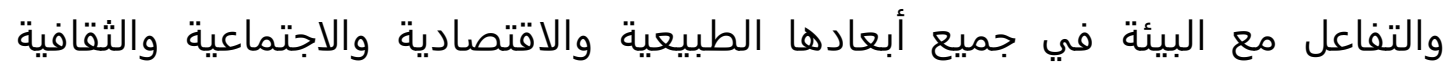
والسياسية والصحية

وهنا يجب وضع الخطط لضمان الشيان التحولات التنموية الإستراتيجية في جميع العلاقات الهيكلية للجامعة ضمن تشكيلاتها العلمية والإدارية المختلفة وبين وظائهائفها الأساسية في التياتية التعليم العالي والبحث العلمي.

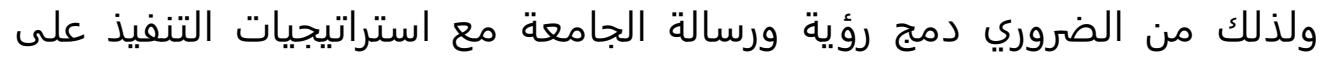

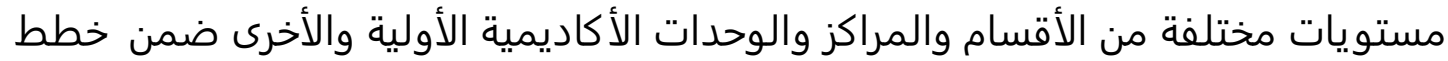

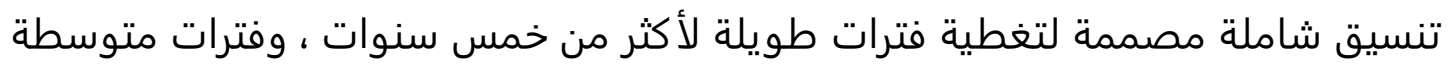

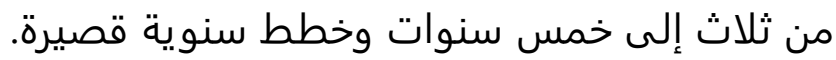

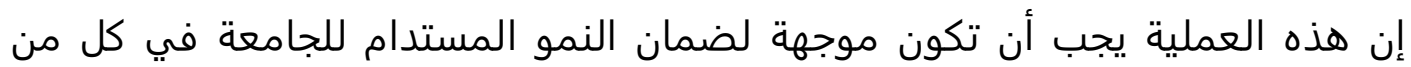
القدرات الإنتاجية والاستيعابية على السواء ـ السكون 